\title{
Article \\ GC- and UHPLC-MS Profiles as a Tool to Valorize the Red Alga Asparagopsis armata ${ }^{\dagger}$
}

\author{
Diana C. G. A. Pinto ${ }^{1, * \mathbb{D}}$, Marie L. Lesenfants ${ }^{2}$, Gonçalo P. Rosa ${ }^{1,2,3} \mathbb{D}$, Maria Carmo Barreto ${ }^{2,3} \mathbb{D}$, \\ Artur M. S. Silva ${ }^{1}\left(\mathbb{D}\right.$ and Ana M. L. Seca ${ }^{1,2,3}$ (D)
}

1 LAQV-REQUIMTE \& Department of Chemistry, Campus de Santiago, University of Aveiro, 3810-193 Aveiro, Portugal; goncalo.p.rosa@uac.pt (G.P.R.); artur.silva@ua.pt (A.M.S.S.); ana.ml.seca@uac.pt (A.M.L.S.)

2 Faculty of Sciences and Technology, University of Azores, Rua Mãe de Deus, 9501-321 Ponta Delgada, Portugal; lesenfantsmarie@hotmail.com (M.L.L.); maria.cr.barreto@uac.pt (M.C.B.)

3 cE3c-Centre for Ecology Evolution and Environmental Changes, Azorean Biodiversity Group, Rua Mãe de Deus, 9501-321 Ponta Delgada, Portugal

* Correspondence: diana@ua.pt; Tel.: +351-234-401407

+ To the memory of Professor Ana I. Neto.

Citation: Pinto, D.C.G.A.; Lesenfants, M.L.; Rosa, G.P.; Barreto, M.C.; Silva, A.M.S.; Seca, A.M.L. GC- and UHPLC-MS Profiles as a Tool to Valorize the Red Alga Asparagopsis armata. Appl. Sci. 2022, 12, 892. https://doi.org/10.3390/ app12020892

Academic Editor: Magdalena Biesaga

Received: 26 December 2021

Accepted: 13 January 2022

Published: 16 January 2022

Publisher's Note: MDPI stays neutral with regard to jurisdictional claims in published maps and institutional affiliations.

Copyright: (C) 2022 by the authors. Licensee MDPI, Basel, Switzerland. This article is an open access article distributed under the terms and conditions of the Creative Commons Attribution (CC BY) license (https:// creativecommons.org/licenses/by/ $4.0 /)$.

\begin{abstract}
Asparagopsis armata Harvey is a red alga native from the southern hemisphere and then introduced in the Mediterranean Sea and the Atlantic Ocean, including the Azores Archipelago, where it is considered an invasive alga. Some studies show that the extracts exhibit antimicrobial and antifouling activities, and it is incorporated in some commercialized cosmetic products. (e.g., Ysaline $\left.{ }^{\circledR}\right)$. However, knowledge of this species chemical composition is scarce. The GC-MS and UHPLC-MS profiles of both the nonpolar and polar extracts were established to contribute to this problem solution. According to the results, A. armata is rich in a great structural variety of halogenated lipophilic and aromatic compounds, some of them identified here for the first time. In the lipophilic extract, 25 compounds are identified, being the halogenated compounds and fatty acids, the two major compound families, corresponding to $54.8 \%$ and $35.7 \%$ of identified compounds (224 and $147 \mathrm{mg} / 100 \mathrm{~g}$ of dry algae, respectively). The 1,4-dibromobuten-1-ol and the palmitic acid are the two most abundant identified compounds (155 and $83.4 \mathrm{mg} / 100 \mathrm{~g}$ of dry algae, respectively). The polar extract demonstrated the richness of this species in brominated phenolics, from which the cinnamic acid derivatives are predominant. The results obtained herein open new perspectives for valuing the $A$. armata as a source of halogenated compounds and fatty acids, consequently improving its biotechnological and economic potential. Promoting this seaweed and the consequent increase in its demand will contribute to biodiversity conservation and ecosystem sustainability.
\end{abstract}

Keywords: Asparagopsis armata; Rhodophyta; GC-MS; UHPLC-MS; dibrominated compounds; 1,4-dibromobuten-1-ol; palmitic acid; brominated phenolics; red seaweed; invasive seaweed

\section{Introduction}

Marine organisms live in complex habitats and are often at the mercy of too variable environmental conditions. To protect themselves from predators, competitors, and many other threats, sea creatures were forced to develop protective mechanisms that include producing a vast number of bioactive compounds, many of which are unique in chemical structure and biological function [1,2]. Seaweeds are among the most explored marine organisms due to their richness in bioactive compounds [3]. However, there are still several species for which the chemical profile is unknown, and Asparagopsis armata is one example.

Asparagopsis species belong to the phylum Rhodophyta (red seaweeds), order Bonnemaisoniales, genus Asparagopsis with three taxonomically accepted species: A. armata Harvey, A. svedelii Taylor, and A. taxiformis Trevisan [4]. Asparagopsis taxiformis has been used as food by Hawaiians [5] while $A$. armata is commercially farmed in northern Europe 
to extract bioactive molecules [6]. Asparagopsis armata is native to Australia and is now widely distributed from the North Atlantic to the coast of Senegal and in the Mediterranean basin [7]. This seaweed seems to exhibit an ecological advantage due to its toxic metabolites that affect the competing algae fixation, forming monospecific coverages, reducing the habitat's species richness, and causing an indirect economic impact by negatively affecting fishing and aquaculture [8]. Despite its negative impact, $A$. armata is commercially farmed in northern Europe to extract bioactive molecules such as sulphated polysaccharides with iodine and bromine groups [6], that are applied as a natural preservative in cosmetics and products to anti-acne treatment (e.g., Invincity ${ }^{\circledR}$ ). In Azores, this invasive seaweed presents an enormous rate of biomass production for which there is no use. Uses such as food or technological application that increase their commercial value and thus create a dynamic that mitigates the negative effects mentioned above are essential.

Although several studies have been published on the biological activity of $A$. armata extracts showing their potential as a source of natural compounds with antiviral, antimicrobial, and antifouling activity [9-11], there are few published works dedicated to the characterization of secondary metabolites existing in the extracts of this species, apart from sterols and volatile halogenated compounds [12-14]. Herein we present and discuss the composition of the polar and lipophilic extracts of $A$. armata, obtained by greener and more efficient methodologies and using GC-MS and UHPLC-MS as tools for separation and identification of the metabolites present.

\section{Materials and Methods}

\subsection{Chemicals}

The following chemicals are used as standards for UHPLC-MS analysis: 2-bromopropionic acid, 2-bromo-5-methoxybenzoic acid and methyl 2-bromo-5-methoxybenzoate were purchased from Alfa Aesar (Kandel, Germany). 2-Bromobenzaldehyde and 3-bromobenzaldehyde were purchased from Sigma-Aldrich GmbH (Darmstadt, Germany). 2'-Bromoacetophenone was obtained from TCI (Oxford, UK). Caffeic, $p$-coumaric, and chlorogenic acids were supplied by Acros Organics (Geel, Belgium).

UHPLC mobile phase eluents: formic acid and acetonitrile HPLC-grade solvents were purchased from Panreac (Barcelona, Spain), and ultrapure water was obtained by a Direct- $Q^{\circledR}$ water purification system (Merck Life Science, Darmstadt, Germany). All other chemicals were of analytical grade.

Solvents used for GC-MS analysis were purchased from Panreac and Acros Organics and were of analytical grade. Chemicals such as $\mathrm{N}, \mathrm{O}$-bis(trimethylsilyl)trifluoroacetamide (BSTFA) (99\%) and trimethylsilyl chloride (TMSCl) (99\%), purchased from Sigma-Aldrich, were used as derivatization agents. Octadecane $(99 \%)$, eicosane $(99 \%)$, palmitic acid $(99 \%)$, stearic acid (>97\%), (Z,Z) 9,12-octadecadienoic acid (99\%), 1-bromononane (98\%), 1,8-dibromooctane (98\%), ( $3 \beta$ ) cholest-5-en-3-ol (99\%), 1-octadecanol $(99 \%)$, and 1-mono palmitin (99\%) were purchased from Sigma-Aldrich and used as standards to qualitative and quantitative GC-MS analysis.

\subsection{Plant Material and Extracts Preparation}

Asparagopsis armata Harvey (on gamethophyte phase) was collected in June 2017, in the intertidal zone of S. Miguel Island coast, in Ponta Delgada, Azores. Prof. Ana Isabel Neto, expert on seaweeds from University of Azores, was responsible for the taxonomic identification of the harvested alga. A voucher specimen (SMG-2017-06) was deposited in Ruy Telles Palhinha Herbarium (AZB).

Asparagopsis armata sample was cleaned from salt and epiphytes, drained between sheets of absorbent paper, and cut into pieces approximately $1 \mathrm{~cm}$ long. Fresh algae after draining contains $92.9 \%( \pm 0.97 \%)$ of water.

Dried A. armata (231.06 g) were obtained from fresh material by air drying, protected from light, and then dried in an oven with forced ventilation at $40^{\circ} \mathrm{C}$, until constant weight. 
The lipophilic extract (extract A) was prepared from $229.2 \mathrm{~g}$ of dried seaweed by maceration (1:10 algae:dichloromethane) at room temperature, under stirring and in the dark, for 3 cycles of 3 days each, with solvent renewal at the end of each cycle. The solvent from the combined extraction steps was first evaporated with a rotary vacuum evaporator at $40{ }^{\circ} \mathrm{C}$ and then dryed under vacuum at room temperature (yield 1.25\%).

From fresh $A$. armata, collected from the same place and date, several polar extracts were prepared, using different polar solvents (ethanol, ethanol:water (50\%), and water) and different methods of extraction (maceration, ultrasounds, and microwave) in order to optimize the extraction procedure according to the Table 1.

Table 1. Experimental conditions used in the preparation of the A. armata polar extracts.

\begin{tabular}{cccc}
\hline Polar Extracts & Extraction Method & Time/Temperature & Solvent \\
\hline $\mathbf{1}$ & Maceration & $1 \mathrm{~h} /$ boiling & $\mathrm{H}_{2} \mathrm{O}^{1}$ \\
$\mathbf{2}$ & Maceration & $24 \mathrm{~h} / \mathrm{room}$ temp. & $\mathrm{H}_{2} \mathrm{O}^{1}$ \\
$\mathbf{3}$ & Maceration & $24 \mathrm{~h} / \mathrm{room}$ temp. & Ethanol $^{1}$ \\
$\mathbf{5}$ & Maceration & $24 \mathrm{~h} / \mathrm{room} \mathrm{temp.}$ & Ethanol/ $\mathrm{H}_{2} \mathrm{O}(1: 1)^{1}$ \\
$\mathbf{6}$ & Microwave & $10 \mathrm{~min} / 50{ }^{\circ} \mathrm{C}$ & Ethanol/ $\mathrm{H}_{2} \mathrm{O}(1: 1)^{2}$ \\
$\mathbf{7}$ & Ultrasounds & $10 \mathrm{~min} / \mathrm{room} \mathrm{temp.}$ & Ethanol/ $\mathrm{H}_{2} \mathrm{O}(1: 1)^{2}$ \\
$\mathbf{8}$ & Microwave & $10 \mathrm{~min} / 50{ }^{\circ} \mathrm{C}$ & Ethanol $^{2}$
\end{tabular}

${ }^{1}$ The proportion algae:solvent was $1 \mathrm{~g}: 4 \mathrm{~mL} .{ }^{2}$ The proportion algae:solvent was $1 \mathrm{~g}: 10 \mathrm{~mL}$.

The dried polar extracts were obtained after evaporation and/or lyophilization. The yields obtained are shown in the Table 2.

Table 2. Extraction yield of the polar A. armata extracts prepared.

\begin{tabular}{cc}
\hline Polar Extracts Prepared & Extraction Yield (g Extract/100 g Fresh Alga) \\
\hline $\mathbf{1}$ & $1.7 \pm 0.1$ \\
$\mathbf{2}$ & $1.7 \pm 0.2$ \\
$\mathbf{3}$ & $1.8 \pm 0.1$ \\
$\mathbf{4}$ & $1.6 \pm 0.1$ \\
$\mathbf{5}$ & $1.6 \pm 0.4$ \\
$\mathbf{6}$ & $1.3 \pm 0.1$ \\
$\mathbf{7}$ & $1.9 \pm 0.3$ \\
$\mathbf{8}$ & $2.0 \pm 0.2$ \\
\hline
\end{tabular}

\subsection{Biologic Activities}

The following paragraphs present the main experimental details of each of the bioactivity assays such as range of concentrations tested, and the positive controls used. A more detailed description of each of the methods employed can be found in Zárate et al. [15].

\subsubsection{DPPH Scavenging Activity}

Antioxidant activity was assayed by the DPPH (1,1-diphenyl-2-picryl-hydrazyl) radical scavenging assay [16]. The extracts were tested at concentrations ranging between $0.244 \mu \mathrm{g} / \mathrm{mL}$ and $250 \mu \mathrm{g} / \mathrm{mL}$ in methanol. Trolox, at concentrations ranging from 0.100 to $100 \mu \mathrm{g} / \mathrm{mL}$, was used as the positive control.

\subsubsection{ABTS Scavenging Activity}

A microplate adaptation of the method by Re et al. [17] was adopted to perform the ABTS radical scavenging assay. The extracts were tested in a range of concentrations of 0.244 to $250 \mu \mathrm{g} / \mathrm{mL}$, and the positive control was Trolox $(0.100-100 \mu \mathrm{g} / \mathrm{mL})$. 


\subsubsection{Ferric Chelating Activity}

The $\mathrm{Fe}^{2+}$ chelating ability of the extracts was assayed by the ferrous iron-ferrozine complex method [18]. The positive control used was EDTA $(0.195-100 \mu \mathrm{g} / \mathrm{mL})$. Samples were assayed at serial concentrations between 0.244 and $250 \mu \mathrm{g} / \mathrm{mL}$.

\subsubsection{Anticholinesterasic Activity}

A modification of the method described by Ellman et al. [19] and Arruda et al. [20] was used for measuring the extracts' ability to inhibit the activity of acetylcholinesterase (AChE) and butyrylcholinesterase (BuChE). The algal extracts were tested at concentrations ranging from 0.293 to $150 \mu \mathrm{g} / \mathrm{mL}$ and compared to the positive control donepezil $(0.010-5.0 \mu \mathrm{g} / \mathrm{mL})$.

\subsubsection{Inhibition of Tyrosinase Activity}

The extracts were assayed by adapting the tyrosinase inhibition method described by Shimizu et al. [21] and modified by Manosroi et al. [22]. Serial concentrations of the extracts $(0.488 \mu \mathrm{g} / \mathrm{mL}$ to $250 \mu \mathrm{g} / \mathrm{mL}$ dissolved in $100 \mathrm{mM}$ phosphate buffer, $\mathrm{pH} 6.8$ were tested. Kojic acid at $0.293-150 \mu \mathrm{g} / \mathrm{mL}$ was used as positive control.

\subsubsection{Inhibition of Collagenase Activity}

The anti-collagenase activity was assayed through an adaptation of the method of Mandl et al. [23]. The extracts and the reference compound EDTA were tested with concentrations ranging between $15.6-250 \mu \mathrm{g} / \mathrm{mL}$.

\subsubsection{Inhibition of Elastase Activity}

A modified version of the described by Ndlovu et al. [24] was used to measure the inhibition of elastase activity by the extracts. The concentration of extract used in the assay ranged from $0.488 \mu \mathrm{g} / \mathrm{mL}$ to $250 \mu \mathrm{g} / \mathrm{mL}$. N-Methoxysuccinyl-Ala-Ala-Pro-chloromethyl ketone at $0.019-20 \mu \mathrm{g} / \mathrm{mL}$ was used as a positive control.

\subsection{UHPLC-DAD-ESI-MS/MS ${ }^{n}$ Characterization of A. armata Aqueous Extract}

A methanolic solution of $A$. armata aqueous extract (prepared under the experimental conditions described in Table 1 for extract 2 and then lyophilized) was analyzed using an UHPLC-ESI-DAD/MS apparatus. The column used was a thermo scientific hypersil gold column $(1000 \mathrm{~mm} \times 20 \mathrm{~mm})$ with a part. size of $1.9 \mu \mathrm{m}$ at $30^{\circ} \mathrm{C}$. The mobile phase was composed of (A) $0.1 \%$ formic acid aqueous solution $(v / v)$ and (B) acetonitrile, and the flow rate was $0.2 \mathrm{~mL} / \mathrm{min}$. The solvent gradient started with $5 \%$ of solvent A over $14 \mathrm{~min}$ followed by $40 \%$ of solvent A for $2 \mathrm{~min}, 100 \%$ over $7 \mathrm{~min}$ and finally $5 \%$ over $10 \mathrm{~min}$. The injection volume was $2 \mu \mathrm{L}$, and the chromatographic profiles were documented at $280 \mathrm{~nm}$. The mass spectrometer used was an LTQ XL linear ion trap 2D equipped with an orthogonal electrospray ion source (ESI). The equipment was operated in negative-ion mode with electrospray ionization source of $5.00 \mathrm{kV}$ and ESI capillarity temperature of $275^{\circ} \mathrm{C}$. The full scan covered a mass range of $50-2000 \mathrm{~m} / \mathrm{z}$. The identification of individual phenolic compounds by UHPLC-MS was achieved by comparing with data available on the literature and interpretation of the MS fragmentation.

\subsection{GC-MS Analysis of A. armata Dichloromethan Extract}

Before GC-MS analysis, four replicates of dried dichloromethane extract of $A$. armata (extract A, nearly $20 \mathrm{mg}$ each), was dissolved in $1 \mathrm{~mL}$ of dichloromethane, added the internal standard (octadecane) and was silylated using $250 \mu \mathrm{L}$ of pyridine, $250 \mu \mathrm{L}$ of BSTFA, and $50 \mu \mathrm{L}$ of $\mathrm{TMSCl}$ in a screw glass tube at $70^{\circ} \mathrm{C}$ during $30 \mathrm{~min}$. This derivatization procedure is well known $[25,26]$ and allows the hydroxyl groups that may exist in the extract constituents to be transformed into silyloxyl groups. Thus, compounds with $-\mathrm{OH}$ substituents will be detected by GC-MS analysis as silylated derivatives which are more volatile, stable, and less polar $[25,26]$. 
Each replicate was analyzed by GC-MS twice using a QP2010 Ultra Shimadzu apparatus with Xcalibur software, equipped with a DB-5- J \&W capillary column $(30 \mathrm{~m} \times 0.25 \mathrm{~mm}$ i.d. and a film thickness of $0.25 \mu \mathrm{m}$ ). The injection was in split mode. The temperature of the column was $70{ }^{\circ} \mathrm{C}$ during $2 \mathrm{~min}$, at $3.5^{\circ} / \mathrm{min}$ until $120^{\circ} \mathrm{C}$, at $9^{\circ} / \mathrm{min}$ until $170{ }^{\circ} \mathrm{C}$, $170{ }^{\circ} \mathrm{C}$ during $10 \mathrm{~min}$, at $9^{\circ} / \mathrm{min}$ until $300^{\circ} \mathrm{C}$, which was maintained for $6 \mathrm{~min}$. Injector temperature was at $320^{\circ} \mathrm{C}$, and the transfer-line temperature was at $200{ }^{\circ} \mathrm{C}$. The mass spectrometer was operated in the EI mode with energy of $70 \mathrm{eV}$, and data were collected at a rate of $1 \mathrm{scan} \mathrm{s}^{-1}$ over a range of $m / z 50-1000$. The carrier gas was helium (purity of $99.995 \%)$ at $1.2 \mathrm{~mL} / \mathrm{min}$.

The compounds were identified, from total ion chromatogram, by comparing the retention times and by comparing their mass spectra with (i) those existing in the MS databases of Wiley229, NIST14, and Shimadzu Pesticide Library; (ii) those published in the literature and by analyzing the fragmentation pattern; (iii) those obtained in the same experimental conditions to standard compounds.

Quantitative analysis was carried out using internal standard method (octadecane, $28.68 \mathrm{~min}$ ), by intrapolation on the calibration curves obtained with at least 4 distinct but known concentrations of representative standards of each family of organic compounds identified in the dichloromethane extract (namely, palmitic acid, stearic acid, $(Z, Z)$ 9,12-octadecadienoic acid, 1-octadecanol, monopalmitin, cholesterol, sitosterol, phenyl acetic acid, 1,8-dibromooctane, 1-bromononane) relative to octadecane. The correlation coefficient $\left(\mathrm{r}^{2}\right)$ of each calibration curve was greater than 0.99 . All standards with hydroxyl substituents were subjected to the silylation procedure described above.

\section{Results and Discussion}

\subsection{Asparagopsis armata Polar Extracts Yield and Chemical Diversity}

Extracts from fresh A. armata were prepared using polar solvents (water, ethanol) and different energy sources according to the data present in Table 1 . The yields of extractions are presented in Table 2. Preparing polar extracts from fresh instead of dry seaweed has the additional advantage of circumventing the difficulties of drying seaweed and grinding after drying. The alga has a high-water content (92.9\%), and the drying process is prolonged. However, no signs of chemical degradation were evident (no changes in color or observed microorganism development). After drying, the seaweed becomes extremely hard, requiring very robust equipment for its grinding.

The different methods and solvents tested reveal identical performance in terms of extraction yield.

Considering the yields obtained and the more sustainable experimental conditions (economically and environmentally "greener"), the profiles of the most interesting extracts were qualitatively analyzed by UHPLC-MS, with the most relevant results shown in Figure 1.

The chemical profiles of the ethanol extracts (extracts 7 and 8 ) are very similar, being both ultrasound and microwave the most selective extraction method. The use of ethanol under microwave energy extracted almost exclusively one compound. Although it was not our aim to identify this compound, its isotopic pattern and $m / z$ in the mass spectra suggests that it is a 2,3-diphenylpropanoic acid derivative, having two hydroxyl groups and four bromine atoms distributed in the aromatic rings ([M-H $]^{-} \mathrm{m} / z$ 568/570/572/574/576). Due to the fragment with $\mathrm{m} / z 319 / 321 / 323$, we suggest that each aromatic ring possesses one hydroxyl group and two bromine atoms.

The chemical profile of the water extracts (extracts 1 and 2 ) showed greater chemical diversity. Thus, the extraction method must be chosen according to the intended application to the extracted compounds that are different according to the method used. If the extraction time is the most relevant, it should choose ultrasound extraction since it is cheaper than microwave extraction, which requires a more expensive apparatus. Using water extraction by maceration at room temperature will be cheaper and allow chemically richer extracts. 


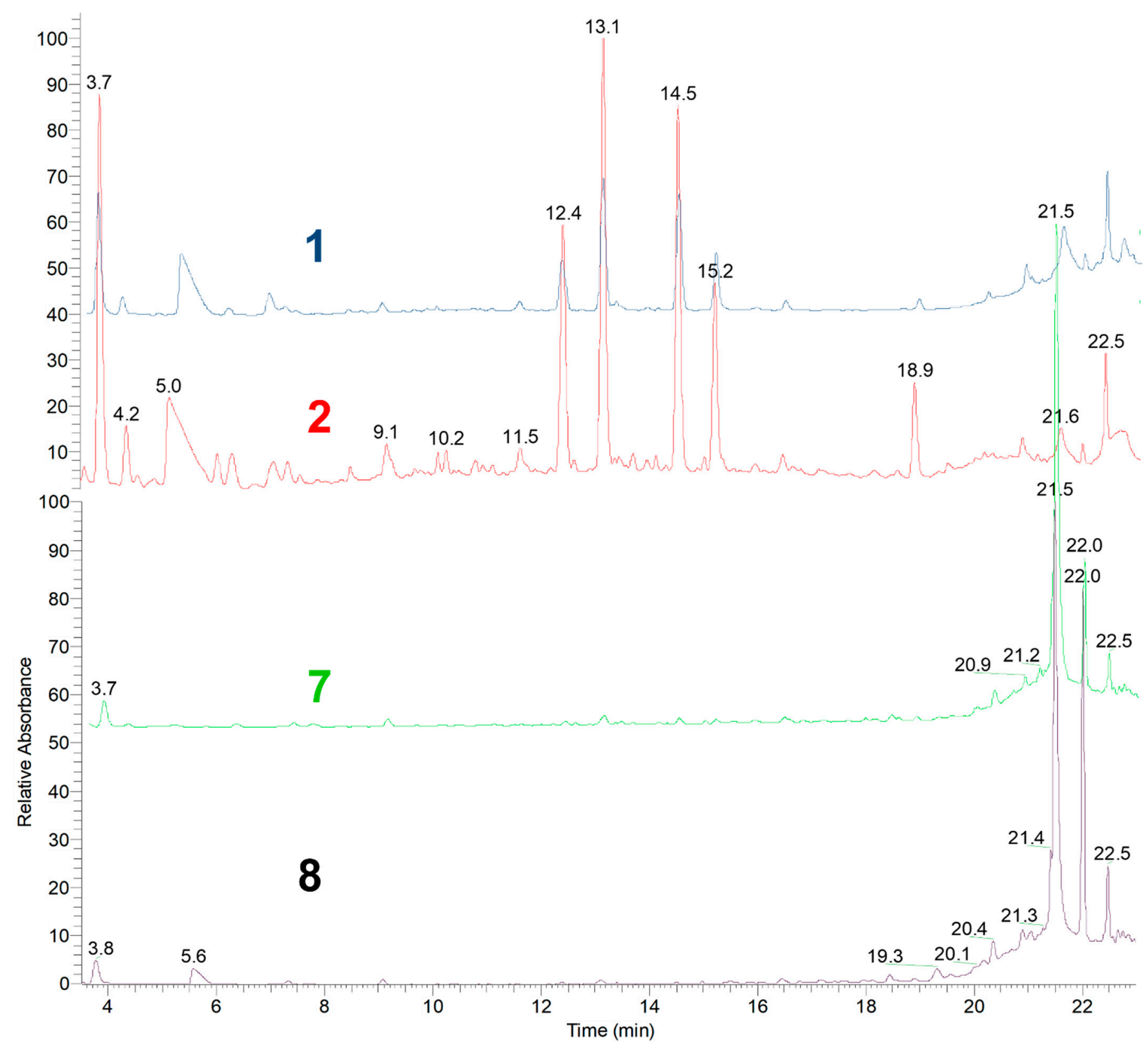

Figure 1. UHPLC chromatograms of greener A. armata polar extract with higher yield, recorded at $280 \mathrm{~nm}$.

As this work intends to study the chemical profile of the polar extract of A. armata, the characterization of the chemical composition of the aqueous extract obtained by maceration at room temperature (extract 2 ) constitutes a significant scientific contribution to knowledge about new polar secondary metabolites in this alga.

\subsection{Biological Activities of Asparagopsis armata Extracts}

Considering the potential application of $A$. armata extracts in the cosmetic industry, the dichloromethane extract (extract A) and the aqueous extract (extract 2), which are in our perspective the most interesting ones, were evaluated for their potential as anti-aging agents. In fact, if we consider some green chemistry aspects, such as extraction yields and energy consumption, these extracts are the best option. Moreover, their chemical profile characterization was achieved.

In this regard, the antioxidant, antiacetylcholinesterase, and antibutyrylcolinesterase activities of extract A were evaluated. Regarding the antioxidant activity, this extract demonstrated an interesting ability to scavenge both the DPPH and ABTS radicals $(23.6 \pm 2.6 \%$ 
and $31.4 \pm 2.8 \%$, respectively), if we compare with the positive control values (Troloxinhibition of DPPH $89.7 \pm 0.5 \%$ and inhibition of ABTS $92.4 \pm 0.2 \%$ ). However, these values were obtained at concentrations of $250 \mu \mathrm{g} / \mathrm{mL}$, and it was not possible to calculate $\mathrm{EC}_{50}$ value for extract $\mathrm{A}$. Concerning the cholinesterases inhibition, the extract $\mathrm{A}$ showed, at a concentration of $150 \mu \mathrm{g} / \mathrm{mL}$, inhibition values of $17.1 \pm 2.3 \%$ and $18.9 \pm 2.0 \%$, respectively for acetylcholinesterase and butyrylcholinesterase. Again, it is imperative to highlight that it was impossible to obtain the $\mathrm{EC}_{50}$ and the positive control value for donepezil at a concentration of $2 \mu \mathrm{g} / \mathrm{mL}$ was $95.2 \pm 0.4 \%$.

Regarding the extract 2 biological assays, we evaluated the ferric chelating ability, the antioxidant, anticollagenase, and antielastase activities. All the activities were evaluated using $250 \mu \mathrm{g} / \mathrm{mL}$ extract concentration, and the $\mathrm{EC}_{50}$ could not be obtained. The extract ability to scavenge the DPPH radical and to chelate iron(III) can be considered low and moderate, with percentage inhibition values of $1.47 \pm 0.42 \%$ and $7.75 \pm 0.44 \%$, respectively for DPPH (trolox $89.71 \pm 0.50 \%$, concentration of $250 \mu \mathrm{g} / \mathrm{mL}$ ) and ferric chelating (EDTA $93.73 \pm 0.24 \%$, concentration of $100 \mu \mathrm{g} / \mathrm{mL}$ ) assays. In the case of anticollagenase, the same extract showed an inhibition percentage of $7.42 \pm 1.79 \%$, which was much lower than the value for positive control EDTA $(96.31 \pm 1.20 \%)$. Finally, the extract inhibited elastase by $43.20 \pm 2.58 \%$ at a $250 \mu \mathrm{g} / \mathrm{mL}$ concentration, an interesting value, although not comparable to the positive control, $\mathrm{N}$-methoxy succinil-Ala-Ala-Pro-Val-chloromethyl ketone which at a $20 \mu \mathrm{g} / \mathrm{mL}$ inhibited the enzyme by $95.51 \pm 3.96 \%$.

Although the results of the bioassays were not exceptional, it is possible to conclude that $A$. armata produce bioactive metabolites, and we can infer that their isolation will improve the activity.

\subsection{UHPLC-MS Characterization of A. armata Aqueous Extract}

Given the above discussed, the aqueous extract obtained at room temperature (extract 2) was analyzed by UHPLC-MS in the negative mode and showed the presence of several phenolic compounds (Figure 2 and Table 3).

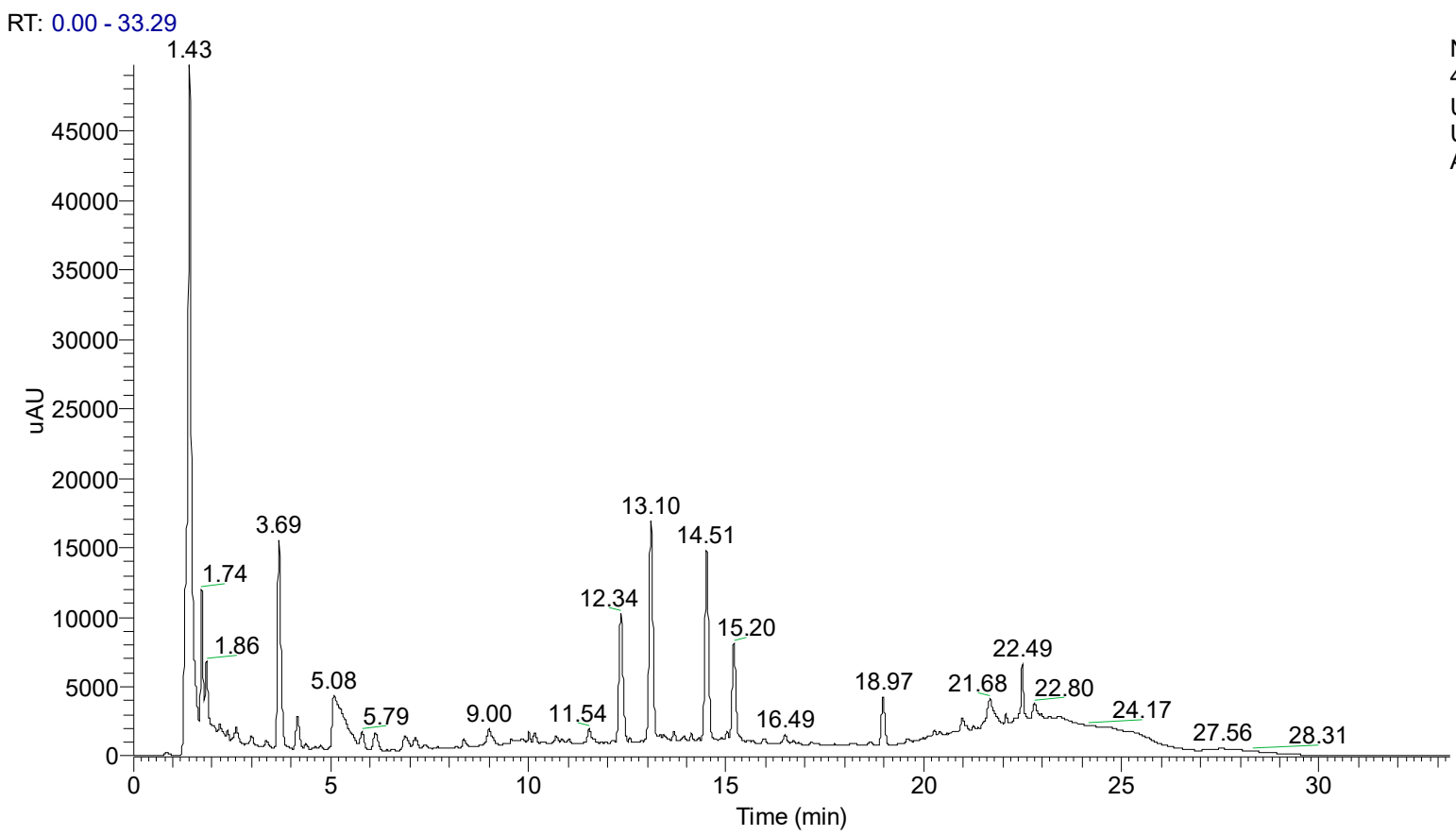

NL: 4.97E4 UV_VIS_4 UV 4 A_a_a

Figure 2. UHPLC chromatogram of $A$. armata aqueous extract, recorded at $280 \mathrm{~nm}$.

The most noticeable aspect of the UHPLC-MS profile is the richness in compounds having bromine atoms (Table 3 and Figure 3), aspect that it is not completely new in view of the publications concerning A. armata [11,27] and other red algae [28-30]. 
Table 3. Tentatively identified compounds on A. armata aqueous extract by UHPLC-MS.

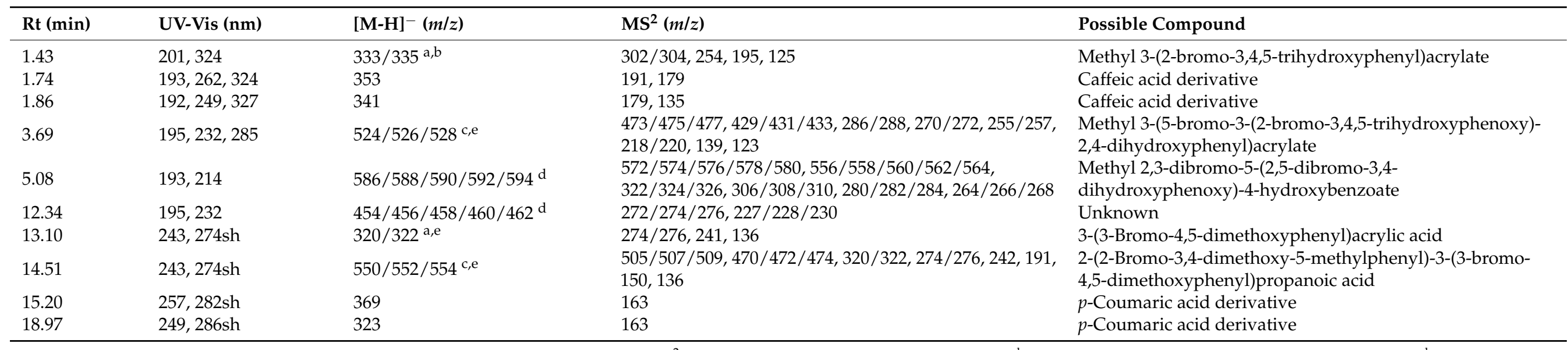

$\mathrm{Rt}=$ retention time, $[\mathrm{M}-\mathrm{H}]^{-}=$pseudomolecular and $\mathrm{MS}^{2}=$ fragment ions, ${ }^{\mathrm{a}}$ ion cluster for one bromine, ${ }^{\mathrm{b}}$ adduct with formic acid, ${ }^{\mathrm{c}}$ ion cluster for two bromine, ${ }^{\mathrm{d}}$ ion cluster for four
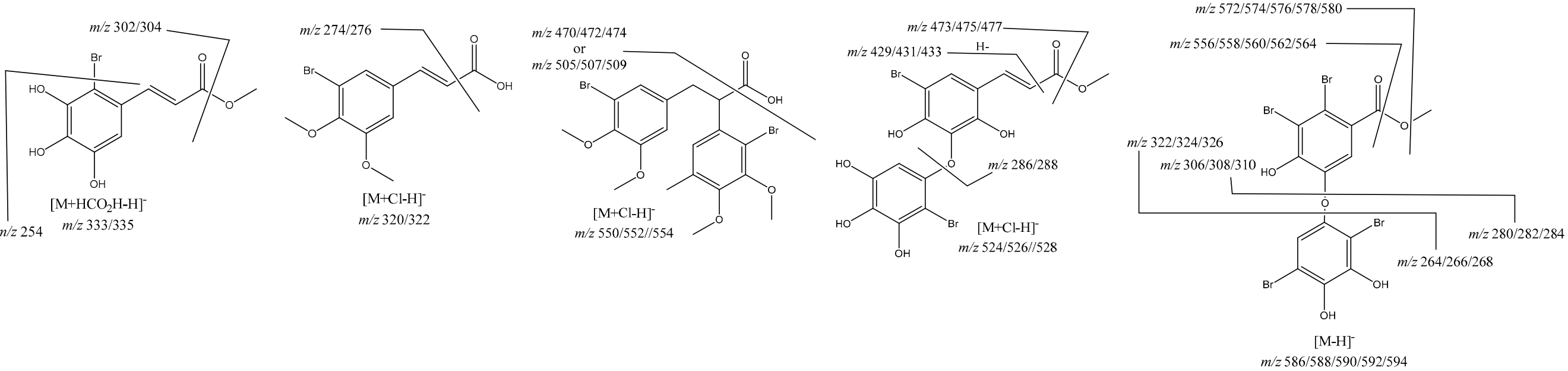

(a)

(b)

(c)

Figure 3. (a) Proposed structures for monobromide derivatives; (b) proposed structures for dibromide derivatives; (c) proposed structure for tetrabromide derivative. 
Among the identified compounds are four cinnamic acid derivatives, specifically from caffeic and $p$-coumaric acids (Table 3), prevalent compounds produced by natural resources, including seaweeds and other marine organisms [31,32]. The fragments observed in $\mathrm{MS}^{2}$, $m / z 179$, and $m / z 163$ are an essential clue to establish that the compounds are respectively caffeic and $p$-coumaric acid derivatives (Table 3 ).

The other metabolites present in the extract are brominated derivatives, and the compound with a retention time of 12.34 min could not be identified, but the isotopic pattern suggests that it has four bromine atoms (Table 3). A structure was proposed for the remaining five metabolites (Figure 3) based on the pseudomolecular ion, isotopic pattern, and fragment ions observed. However, we should highlight that we did not establish the aromatic rings substitution pattern, and in the proposed structures, the substituents order was made considering the most common ones described in the literature $[28,30]$.

Compounds eluted at $1.43 \mathrm{~min}$ and $13.10 \mathrm{~min}$ were identified as cinnamic acid derivatives bearing one bromine atom (Figure 3a) due to their pseudomolecular ion isotopic pattern (Table 3). Moreover, brominated polyphenols and polymethoxybenzenes are commonly found in seaweeds [30]. The main fragments ions suggest that the compound eluted at $1.43 \mathrm{~min}$ is the methyl 3-(2-bromo-3,4,5-trihydroxyphenyl)acrylate or one isomer, being the fragment ion $\mathrm{m} / \mathrm{z} 254$ obtained through the loss of the bromine atom and the fragment ion $\mathrm{m} / \mathrm{z} 195$ obtained through an extra loss of $\mathrm{CO}_{2} \mathrm{CH}_{3}$. In the case of compound eluted at 13.10 min 3-(3-bromo-4,5-dimethoxyphenyl)acrylic acid, it can be observed the typical loss of $\mathrm{CO}_{2}$ and also the loss of the bromine atom to give the fragment ion $m / z 241$ (Figure 3a).

Next, we identified two compounds, methyl 3-(5-bromo-3-(2-bromo-3,4,5- trihydroxyphenoxy) -2,4-dihydroxyphenyl)acrylate eluted at $3.69 \mathrm{~min}$ and 2-(2-bromo-3,4-dimethoxy-5methylphenyl)-3-(3-bromo-4,5-dimethoxyphenyl)propanoic acid eluted at $14.51 \mathrm{~min}$, both having an ion cluster for two bromine atoms. The main fragment ions confirm the proposed structures (Figure 3b); however, we should again stress that the bromine atoms' position in the aromatic rings was not demonstrated. The fragments just suggest that they are one in each ring.

Finally, we have methyl 2,3-dibromo-5-(2,5-dibromo-3,4-dihydroxyphenoxy)-4hydroxybenzoate (Figure 3c), eluted at $5.08 \mathrm{~min}$, showing an ion cluster for four bromine atoms (Table 3) and presenting fragment ions consistent with the proposed structure. Once more, it is important to highlight that some fragment ions establish that the bromine atoms are equally distributed in the aromatic rings, but their position can be interchanged.

\subsection{GC-MS of Lipophilic Extract}

To prepare the lipophilic extract, in a preliminary study, hexane and dichloromethane solvents were used, and the results (unpublished results) showed that dichloromethane extraction yield was superior to that obtained with hexane under the same experimental conditions. Furthermore, dichloromethane is a widely used non-polar and unspecific solvent capable of dissolving a wide variety of less polar metabolites. Thus, to obtain broader knowledge, the dichloromethane extract (extract A) was selected for analysis by GC-MS to determine the chemical composition of the less polar fraction of A. armata. The results of qualitative and quantitative analysis are summarized in Table 4. 
Table 4. Tentative identified compounds on dichloromethane extract (extract A) from dried A. armata by GC-MS.

\begin{tabular}{|c|c|c|c|c|}
\hline \multirow{2}{*}{ Rt (min) } & \multirow{2}{*}{ Compound Identified * } & \multicolumn{3}{|c|}{ Medium Content (SD) } \\
\hline & & $\mathrm{mg} / 100 \mathrm{mg}$ Extract & mg/100 g Dried Alga & $\mathrm{mg} / \mathrm{kg}$ Fresh Alga \\
\hline \multicolumn{5}{|c|}{ Fatty Acids } \\
\hline 24.1 & Lauric acid (C12:0) ${ }^{b}$ & $0.489(0.024)$ & $6.11(0.30)$ & $4.33(0.21)$ \\
\hline 30.6 & Myristic acid (C14:0) b & $1.88(0.07)$ & $23.5(0.9)$ & $16.6(0.6)$ \\
\hline 34.6 & Pentadecanoic acid $(\mathrm{C} 15: 0)^{b}$ & $0.404(0.012)$ & $5.05(0.14)$ & $3.58(0.10)$ \\
\hline 36.5 & Palmitoleic acid (C16:1) ${ }^{b}$ & $0.767(0.066)$ & $9.59(0.82)$ & $6.80(0.58)$ \\
\hline 36.8 & Palmitic acid $(\mathrm{C} 16: 0)^{\mathrm{a}}$ & $6.67(0.29)$ & $83.4(3.6)$ & $59.2(2.6)$ \\
\hline 39.5 & Oleic acid $(\mathrm{C} 18: 1)^{\mathrm{a}}$ & $1.15(0.13)$ & $14.4(1.6)$ & $10.2(1.1)$ \\
\hline \multirow[t]{2}{*}{39.8} & Stearic acid $(\mathrm{C} 18: 0)^{\mathrm{a}}$ & $0.381(0.017)$ & $4.76(0.21)$ & $3.37(0.15)$ \\
\hline & Total & 11.7 & 147 & 104 \\
\hline \multicolumn{5}{|c|}{ Halogenated Compounds } \\
\hline 4.2 & Chloro acetic acid ${ }^{b}$ & $0.497(0.049)$ & $6.21(0.61)$ & $4.40(0.43)$ \\
\hline 6.1 & Clorobutenol $^{\mathrm{c}}$ & $0.502(0.012)$ & $6.27(0.15)$ & $4.45(0.11)$ \\
\hline 8.5 & 3-Bromoprop-2-enoic acid ${ }^{\mathrm{c}}$ & $1.40(0.20)$ & $17.5(2.51)$ & $12.4(1.78)$ \\
\hline 10.1 & Bromopyruvic acid $^{\mathrm{c}}$ & $0.612(0.061)$ & $7.65(0.77)$ & $5.43(0.54)$ \\
\hline 15.5 & 1,4-Dibromobuten-1-ol ${ }^{\mathrm{c}}$ & $12.4(1.0)$ & $155(12)$ & $110(9)$ \\
\hline 19.1 & Bromotridecenol $^{\mathrm{c}}$ & $0.842(0.048)$ & $10.5(0.6)$ & $7.47(0.42)$ \\
\hline 19.3 & Isomer of bromotridecenol $(19.1 \mathrm{~min})^{c}$ & $0.807(0.061)$ & $10.1(0.8)$ & $7.16(0.54)$ \\
\hline \multirow[t]{2}{*}{23.7} & Isomer of 1,4-dibromobuten-1-ol $(15.5 \mathrm{~min})^{\mathrm{c}}$ & $0.940(0.019)$ & $11.7(0.2)$ & $8.33(0.17)$ \\
\hline & Total & 18.0 & 224 & 159 \\
\hline \multicolumn{5}{|c|}{ Glycerol and derivatives } \\
\hline 15.2 & Glycerol $^{\mathrm{a}, \mathrm{b}}$ & $0.151(0.020)$ & $1.96(0.20)$ & $1.39(0.14)$ \\
\hline 40.4 & Glyceryl-glycoside $^{b}$ & $0.163(0.031)$ & $2.04(0.39)$ & $1.44(0.27)$ \\
\hline 41.5 & 1-Monomyristin ${ }^{b, c}$ & $0.356(0.046)$ & $4.44(0.57)$ & $3.15(0.40)$ \\
\hline \multirow[t]{2}{*}{43.3} & 1-Monopalmitin ${ }^{a}$ & $0.353(0.013)$ & $4.41(0.16)$ & $3.13(0.11)$ \\
\hline & Total & 1.02 & 12.9 & 9.11 \\
\hline \multicolumn{5}{|l|}{ Sterols } \\
\hline 48.4 & Cholesterol $^{\mathrm{a}}$ & $0.617(0.076)$ & $7.71(0.95)$ & $5.47(0.68)$ \\
\hline \multicolumn{5}{|c|}{ Aromatic compounds } \\
\hline 16.1 & Phenyl acetic acid ${ }^{a}$ & $0.683(0.049)$ & $8.54(0.61)$ & $6.06(0.43)$ \\
\hline \multirow[t]{2}{*}{18.6} & 4-Hydroxybenzaldehyde ${ }^{b}$ & $0.158(0.009)$ & $1.97(0.11)$ & $1.40(0.08)$ \\
\hline & Total & 0.841 & 10.5 & 7.46 \\
\hline \multicolumn{5}{|c|}{ Other compounds } \\
\hline 4.7 & Ethyl amine ${ }^{b}$ & $0.058(0.004)$ & $0.727(0.054)$ & $0.516(0.038)$ \\
\hline 8.1 & Glycolic acid $^{b}$ & $0.267(0.037)$ & $3.33(0.47)$ & $2.37(0.33)$ \\
\hline \multirow[t]{3}{*}{25.4} & Heptadecane ${ }^{b}$ & $0.900(0.043)$ & $11.2(0.5)$ & $7.97(0.38)$ \\
\hline & Total & 1.23 & 15.3 & 10.9 \\
\hline & $\begin{array}{l}\text { Rt-Retention time. SD-Stan } \\
\text { as the corresponding TMS de } \\
\text { b comparison with the GC-M } \\
\text { the peaks at } m / z \text { values corre } \\
{ }^{c} \text { interpretation of pattern frag }\end{array}$ & $\begin{array}{l}\text { d deviation. }{ }^{*} \text { All the } \mathrm{c} \\
\text { atives. Compounds we } \\
\text { pectral libraries with si } \\
\text { nding to the characteri } \\
\text { tation of MS spectrum }\end{array}$ & $\begin{array}{l}\text { mpounds possessing hydr } \\
\text { e identified by: a compar } \\
\text { nilarity index higher than } \\
\text { tic fragmentation pattern } \\
\text { ccording to published liter }\end{array}$ & $\begin{array}{l}\text { kyl groups are identifie } \\
\text { on with pure standarc } \\
4 \% \text { and confirmation } \\
\text { f the family in questio } \\
\text { ure. }\end{array}$ \\
\hline
\end{tabular}


The results in Table 4, graphically summarized in Figure 4, clearly show the predominance, in this lipophilic extract, of halogenated compounds (54.8\%), being $40.6 \%$ dibromine mono-unsaturated alcohols and 14.2\% mono-bromine and mono-chloride compounds.

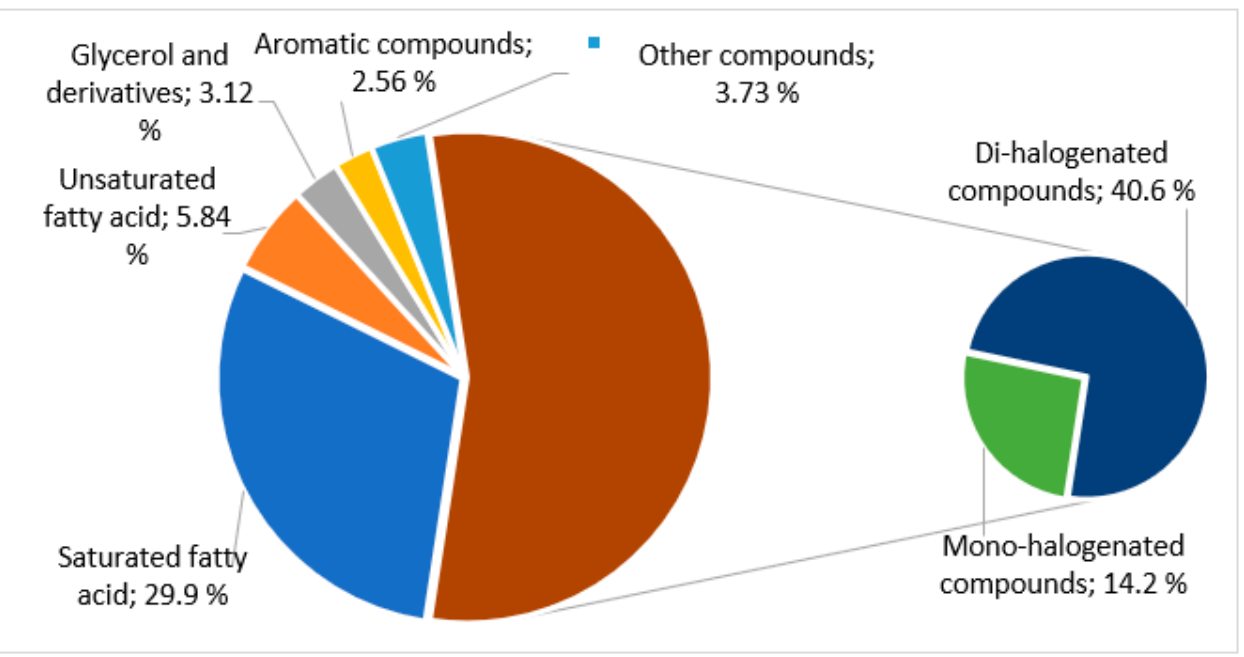

Figure 4. Graphical presentation of the percentage of each class of compounds dichloromethane extract of A. armata.

The most abundant compound in the extract (1,4-dibromobutenol, Rt $15.5 \mathrm{~min}$ ) belongs to this class $(68.8 \%$ of the total halogenated compounds and $37.8 \%$ of the total identified compounds). The presence of one or more halogen atoms, chlorine, or bromine, in the chemical structure of several of the identified compounds is assumed, with a high degree of certainty, from the characteristic isotopic pattern of each chemical element. The bromine exists as two isotopes in approximately equal amounts of atomic mass 79 and 81, while chlorine has 2 isotopes of atomic mass 35 and 37 in a ratio of approximately 3:1.

In the case of the most abundant compound, at Rt $15.5 \mathrm{~min}$, the presence of 2 bromine atoms is deduced from the peak corresponding to molecular ion [M] ${ }^{+\bullet}$ at $m / z$ 300/302/304 (a very weak signal) in the ratio of 1:2:1. The mass spectrum of this compound also shows the base peak at $m / z 75$, corresponding to $\left[\mathrm{HOSi}\left(\mathrm{CH}_{3}\right)_{2}\right]^{+}$, and the second most intense peak at $m / z 285 / 287 / 289$ (also in a 1:2:1 ratio), corresponding to [M-15] ${ }^{+}$(loss of a methyl group from the TMS ether moiety). These signals support the hypothesis that the compound at Rt $15.5 \mathrm{~min}$ is a silylated primary alcohol [33], with two bromine atoms as substituents. Thus, it can be deduced that the compound in the extract will have a molecular mass of 230 corresponding to the chemical formula $\mathrm{C}_{4} \mathrm{H}_{6} \mathrm{OBr}_{2}$, suggesting the presence of a double bond in the basic structure of dibromo butanol. The greatest diagnostic value is the fragments with $m / z$ at $131 / 133$ and $137 / 139$. The presence of these peaks, with identical intensity in each pair, shows that the fragmentation of the molecule gives rise to fragments containing one bromine atom each, being a strong indication of bromine atoms on different carbons. The peak at $m / z 131 / 133$ will correspond to the fragment $\left[\mathrm{C}_{4} \mathrm{H}_{4} \mathrm{Br}\right]^{+}$, resulting from loss of $\mathrm{HBr}$ by the molecular ion, following a $\delta$-chain loss, indicating that the bromine atoms are found in the carbons 1 and 4 . The peak at $m / z 137 / 139$ could result from loss of a methyl from the silyloxyl group, followed by bonding of the resulting siliconium ion to the terminal bromine atom, and a final rearrangement [33] to originate the fragment $\left[\mathrm{BrSi}\left(\mathrm{CH}_{3}\right)_{2}\right]^{+}$.

Comparing the mass spectrum of 1,4-dibromobuten-1-ol (15.5 min) with that exhibited by the compound at $23.7 \mathrm{~min}$, it is concluded that both are dibrominated mono-unsaturated alcohols with molecular formula $\mathrm{C}_{4} \mathrm{H}_{6} \mathrm{OBr}_{2}$, which mean they are isomers. They have a very similar fragmentation pattern $\left[\mathrm{M}-\mathrm{CH}_{3}\right]^{+}$at $\mathrm{m} / \mathrm{z} 285 / 287 / 289,\left[\mathrm{BrSi}\left(\mathrm{CH}_{3}\right)_{2}\right]^{+}$at $\mathrm{m} / z$ 137/139, and the base peak at $m / z 73\left(\left[\mathrm{Si}\left(\mathrm{CH}_{3}\right)_{3}\right]^{+}\right.$, being the last one ubiquitous to the spectra of TMS derivatives. The most significant differences are the absence of signals at $\mathrm{m} / \mathrm{z} 131 / 133$ and 
the presence of the peak at $m / z$ 197/199/201 corresponding to the fragment $\left[\mathrm{C}_{3} \mathrm{H}_{3} \mathrm{Br}_{2}\right]^{+}$, resulting from an $\alpha$-cleavage with retention of the 2 bromine atoms and the double bond on the cation. These fragments suggest that the difference between the compounds at 15.5 and $23.7 \mathrm{~min}$ is the position of the bromo substituents. These two compounds are the only di-halogenated compounds identified in the extract and correspond to $166.2 \mathrm{mg} / 100 \mathrm{~g}$ of dry algae (40.6\% of identified compounds).

The peaks at 19.1 and $19.3 \mathrm{~min}$ also correspond to two unsaturated alcohols silylated, but in this case mono-brominated, as deduced from the isotopic pattern analysis of fragments $[\mathrm{M}-15]^{+}$at $m / z 333 / 335(1: 1) ;\left[\mathrm{C}_{2} \mathrm{H}_{6} \mathrm{SiBr}\right]^{+}$at $m / z 137 / 139(1: 1)$. The peak at $m / z$ 179 on the mass spectra of both isomers, corresponding to the non-brominated fragment $\left[\mathrm{C}_{13} \mathrm{H}_{23}\right]^{+}\left([\mathrm{M}-90-\mathrm{Br}]^{+}\right)$, suggests the same bromine substitution pattern on both isomers. The molecular formula of the two compounds on the extract is $\mathrm{C}_{13} \mathrm{H}_{25} \mathrm{BrO}$, named bromotridecenol. The difference between them should be the position of the double bond, difficult to determine by MS.

The second most abundant halogenated compound $(7.8 \%)$ corresponds to the peak at $8.5 \mathrm{~min}$, identified as 3-bromoprop-2-enoic acid TMS derivative. The mass spectrum shows the signals at $m / z 207 / 209(\sim 1: 1)$, corresponding to the fragment $\mathrm{C}_{5} \mathrm{H}_{8} \mathrm{BrO}_{2} \mathrm{Si}^{+}\left([\mathrm{M}-15]^{+}\right)$ and 137/139 ( 1:1) corresponding to $\left[\left(\mathrm{CH}_{3}\right)_{2} \mathrm{SiBr}\right]^{+}$, both mono-bromine silylated fragments typical from halocarboxylic acids pattern fragmentation [33]. The $m / z$ value of these two fragments differs by 2 units from those observed for 3-bromopropanoic acid, evidencing the existence of a double bond at C2-C3. Moreover, the three signals observed in the spectrum of 3-bromoprop-2-enoic acid TMS derivative at $m / z 143[\mathrm{M}-\mathrm{Br}]^{+}, 75$ (base peak, $\left[\mathrm{HOSi}\left(\mathrm{CH}_{3}\right)_{2}\right]^{+}$) and 53 (loss of trimethylsilanol and $\mathrm{HBr}$ resulting the fragments $\left[\mathrm{C}_{3} \mathrm{H}_{3} \mathrm{O}\right]^{+}$), all corresponding to non-brominate fragments, confirm the proposed identification of compound at $8.5 \mathrm{~min}$. This compound was previously identified on the A. armata as ethyl ester [14].

The presence of halogenated alcohols and carboxylic acids in Asparagopsis species was already reported in the literature [11,14,34]. The results of several studies show that these are toxic metabolites that, in addition to exhibiting antimicrobial activity, confer a competitive advantage over predators and other species [35,36]. Moreover, to our best knowledge, this is the first time that 1,4-dibromobuten-1-ol and its isomer have been reported and quantified in the Asparagopsis genus.

The second most abundant family of compounds was the fatty acids ( $35.8 \%)$, being the content of saturated acids 5.1 times higher than the content of unsaturated acids (Figure 4). This can be an asset since saturated fatty acids seem to have a beneficial effect on the modulation of the immune system on food-borne bacterial infection [37].

The results of Table 4 show that the second most abundant compound is palmitic acid $(20.3 \%)$, being the most plentiful fatty acid (57.0\%). In comparison, the second most abundant fatty acid is myristic acid (16.1\%). These results are in line with those published by Pereira et al. [38] for the same species, where palmitic and myristic acids are, by far, the most abundant fatty acids. Interestingly, in line with this result, the monoacylglycerols of these two acids, monomyristin and monopalmitin, were identified and quantified in the extract (Table 4; Rt $=41.5$ and $\mathrm{Rt}=43.3 \mathrm{~min}$, respectively), representing about $2.1 \%$ of the compounds detected.

As far as unsaturated fatty acids are concerned (Figure 4), the most abundant is oleic acid ((9Z) 9-octadecenoic acid). It is the third most abundant fatty acid (9.83\%), representing only $3.50 \%$ of the identified compounds.

From the point of view of beneficial effects on health, the presence of oleic acid can be considered an asset, while the high content of palmitic acid can be seen as an obstacle to seaweed consumption. However, we draw readers' attention to the fact that data in the literature suggest that the potential adverse effect of saturated acids is controversial and should be reviewed $[39,40]$. Moreover, the results show that $A$. armata can be valued as a source of palmitic acid. In fact, this compound is described as modulating the immune 
response [37] and it is an interesting antifouling agent due to its action against the first bacterial colonies on submerged surfaces [41].

Neither polyunsaturated acid nor unsaturated acids with trans configuration were detected, contrary to what is reported by Pereira et al. [38], where trans-oleic acid is detected in greater amounts than cis-oleic acid, and small amounts of arachidonic and eicosapentaenoic (EPA) acids are also noticed. These discrepancies may be related to geographical, seasonal, and/or environmental factors, but above all, due to the significant differences between sample preparation procedures before GC-MS analysis.

Only one compound from the hydrocarbon family has been identified, the heptadecane (Table 4, Rt $=25.4 \mathrm{~min},[\mathrm{M}]^{+\bullet}$ at $\mathrm{m} / \mathrm{z} 240$;). This alkane represents $2.7 \%$ of the total content of compounds, being the seventh most abundant. Although some hydrocarbons have been identified in the genus Asparagopsis [42], they have a chain of up to 5 carbons, while in this work, a long-chain alkane (17 carbons) is identified for the first time.

Cholesterol was the only sterol detected in the dichloromethane extract of $A$. armata, corresponding to $7.71 \mathrm{mg} / 100 \mathrm{~g}$ of dry seaweed (1.8\% of identified compounds). This result aligns with the literature $[12,13]$ that describes cholesterol as the most abundant sterol in this species. Lopes et al. [13] indicate a total cholesterol content of $28.92 \mathrm{mg} / 100 \mathrm{~g}$ of dry material, a value higher than the one reported here. This difference is justified because cholesterol exists mainly in non-free form as a constituent of the cell membrane, being released during the alkaline hydrolysis to which the sample was submitted in work by Lopes et al. [13]. It should be noted that the sterol content of Asparagopsis species is variable and depends on several factors (e.g., geographic, environmental, and seasonal) but mainly dependent on the life cycle phase [12]. Despite its "bad reputation" as a constituent of food products, cholesterol is a valuable natural product due to its chemical skeleton being easily transformable into new derivatives with diverse applications, such as drug delivery, production of liquid crystals and gelling agents, hormone precursor, and bioactive compounds [43].

\section{Conclusions}

The initial study on applying different methodologies to obtain polar extracts of A. armata showed that the choice of the extraction method would have to consider which compounds are intended to be extracted and the intended application for the obtained extract. The chemical profile of the water extract obtained by maceration (extract 2) has greater chemical diversity and is economically cheaper.

Herein, for the first time, the aqueous and lipophilic A. armata extracts were tested as anti-aging agents with antioxidant and/or enzymatic inhibitors action. The polar extract was the most active, exhibiting the ability to inhibit $43.20 \pm 2.58 \%$ of elastase activity at a $250 \mu \mathrm{g} / \mathrm{mL}$ concentration. On the other hand, although the lipophilic extract is a weak cholinesterase inhibitor, it is a dual inhibitor (it inhibits acetyl and butyryl-cholinesterase identically), which constitutes an advantage concerning its potential as an agent against Alzheimer's Disease.

Qualitative analysis by UHPLC-MS demonstrates that $A$. armata water extract is rich in phenolic compounds bearing bromine atoms; furthermore, the cinnamic acid scaffold is a prominent nucleus. The secondary metabolites herein described may explain the seaweed persistence and absence of predators. Furthermore, the anti- elastase activity mentioned above may be related to these phenolic compounds present in the water extract; nevertheless, more studies are essential.

The analysis of the most lipophilic fraction of $A$. armata (dichloromethane extract) by GC-MS allowed to identify and quantify 25 compounds, seven of them for the 1st time in this species, such as two dibrominated unsaturated alcohols, the 1,4-dibromobuten-1-ol and its isomer with the bromine atoms in different positions (a total of $166.2 \mathrm{mg} / 100 \mathrm{~g}$ of dry algae, $40.6 \%$ of identified compounds); two monobromine unsaturated alcohols, the bromotridecenol and its isomer with double bond on different position (a total of $20.6 \mathrm{mg} / 100 \mathrm{~g}$ of dry algae, 5.0\% of identified compounds); one alkane, the heptadecane (a 
total of $11.2 \mathrm{mg} / 100 \mathrm{~g}$ of dry algae, $2.7 \%$ of identified compounds); and two monoacylglycerols, the monopalmitin and the monomyristin (a total of $8.85 \mathrm{mg} / 100 \mathrm{~g}$ of dry algae, $2.1 \%$ of identified compounds).

The halogenated compounds and fatty acids are the two major compound families in the extract, being the 1,4-dibromobuten-1-ol and the palmitic acid the two most abundant identified compounds ( 155 and $83.4 \mathrm{mg} / 100 \mathrm{~g}$ of dry algae, respectively) and the myristic acid the third most abundant compound ( $23.5 \mathrm{mg} / 100 \mathrm{~g}$ of dry algae). The unsaturated fatty acids family, mainly $9 Z$-octadecenoic acid $(14.4 \mathrm{mg} / 100 \mathrm{~g}$ of dry algae), corresponds to nearly $6 \%$ of the identified compounds.

As it is already known that no completely satisfactory method allows the analysis of the entire range of halogenated compounds of the Asparagopsis species, as they have a wide range of solubilities and boiling points [44], the work presented here is innovative as it allows the identification of a variety of lipophilic and halogenated aromatic compounds structurally distinct from those identified so far in A. armata.

Considering what is already known about the ecotoxicological effect of several halogenated compounds identified in Asparagopsis species [11,45], which give them a competitive advantage, and the commercial value of several scaffold phytochemicals identified in this species, the results obtained herein open new perspectives for valuing the $A$. armata as a source of halogenated compounds and fatty acids with high biotechnological and economic potential.

Valuing invasive species as a source of value-added natural products is an approach that promotes biodiversity conservation and ecosystem sustainability. It increases the algae harvest, allowing the assisted recolonization of free space by native species, because it increases the demand for existing and available biomass.

Author Contributions: Conceptualization, D.C.G.A.P., M.C.B. and A.M.L.S.; formal analysis and investigation, D.C.G.A.P., M.L.L., G.P.R., M.C.B. and A.M.L.S.; writing—original draft preparation, D.C.G.A.P. and A.M.L.S.; writing-review and editing, D.C.G.A.P., G.P.R., M.C.B., A.M.S.S. and A.M.L.S. All authors have read and agreed to the published version of the manuscript.

Funding: This study was financed by ASPAZOR project (DRCT: ACORES-01-0145-FEDER-00060- ASPAZOR); Portuguese National Funds, through FCT-Fundação para a Ciência e a Tecnologia, and as applicable co-financed by the FEDER within the PT2020 Partnership Agreement by funding the LAQVREQUIMTE (UIDB/50006/2020) and the cE3c centre (FCT Unit funding (Ref. UID/BIA/00329/2013, 2015-2018) and UID/BIA/00329/2019).

Institutional Review Board Statement: Not applicable.

Informed Consent Statement: Not applicable.

Data Availability Statement: Not applicable.

Acknowledgments: Thanks are also due to the University of Aveiro and the University of Azores, to Mónica S.G.A. Válega and her support in UHPLC-MS analysis, and to Carlota Ferro for her support in biological activities.

Conflicts of Interest: The authors declare no conflict of interest.

\section{References}

1. Fusetani, N. Marine Natural Products. In Natural Products in Chemical Biology; Civjan, N., Ed.; John Wiley and Sons: New York, NY, USA, 2012; pp. 31-64.

2. Hamed, I.; Özogul, F.; Özogul, Y.; Regenstein, J.M. Marine bioactive compounds and their health benefits: A review. Compr. Rev. Food Sci. Food Saf. 2015, 14, 446-465. [CrossRef]

3. Rosa, G.P.; Sousa, P.; Tavares, W.R.; Pagès, A.K.; Seca, A.M.L.; Pinto, D.C.G.A. Seaweeds secondary metabolites with beneficial health effects: An overview of successes in in vivo studies and clinical trials. Mar. Drugs 2020, 18, 8. [CrossRef]

4. Guiry, G.M. AlgaeBase 2021. World-Wide Electronic Publication. National University of Ireland. Galway. Available online: http:/ / www.algaebase.org (accessed on 1 October 2021).

5. Abbott, I.A. The uses of seaweed as food in Hawaii. Econ. Bot. 1978, 32, 409-412. [CrossRef] 
6. Kraan, S.; Barrington, K.A. Commercial farming of Asparagopsis armata (Bonnemaisoniceae. Rhodophyta) in Ireland. Maintenance of an introduced species? J. Appl. Phycol. 2005, 17, 103-110. [CrossRef]

7. Chualáin, F.N.; Maggs, C.A.; Saunders, G.W.; Guiry, M.D. The invasive genus Asparagopsis (Bonnemaisoniaceae. Rhodophyta): Molecular systematics. morphology. and ecophysiology of Falkenbergia isolates. J. Phycol. 2004, 40, 1112-1126. [CrossRef]

8. Katsanevakis, S.; Wallentinus, I.; Zenetos, A.; Leppäkoski, E.; Çinar, M.E.; Oztürk, B.; Grabowski, M.; Golani, D.; Cardoso, A.C. Impacts of invasive alien marine species on ecosystem services and biodiversity: A pan-European review. Aqua. Invas. 2014, 9, 391-423. [CrossRef]

9. Pinteus, S.; Lemos, M.F.L.; Alves, C.; Silva, J.; Pedrosa, R. The marine invasive seaweeds Asparagopsis armata and Sargassum muticum as targets for greener antifouling solutions. Sci. Total Environ. 2021, 750, 141372. [CrossRef]

10. Pinteus, S.; Alves, C.; Monteiro, H.; Araújo, E.; Horta, A.; Pedrosa, R. Asparagopsis armata and Sphaerococcus coronopifolius as a natural source of antimicrobial compounds. World J. Microbiol. Biotechnol. 2015, 31, 445-451. [CrossRef]

11. Félix, R.; Dias, P.; Félix, C.; Cerqueira, T.; Andrade, P.B.; Valentão, P.; Lemos, M.F.L. The biotechnological potential of Asparagopsis armata: What is known of its chemical composition, bioactivities and current market? Algal Res. 2021, 60, 102534. [CrossRef]

12. Combaut, G.; Bruneau, Y.; Codomier, L.; Teste, J. Comparative sterols composition of the red alga Asparagopsis armata and its Tetrasporophyte Falkenbergia rufolanosa. J. Nat. Prod. 1979, 42, 150-151. [CrossRef]

13. Lopes, G.; Sousa, C.; Bernardo, J.; Andrade, P.B.; Valentão, P.; Ferreres, F.; Mouga, T. Sterol profiles in 18 macroalgae of the portuguese coast. J. Phycol. 2011, 47, 1210-1218. [CrossRef] [PubMed]

14. McConnell, O.; Fenical, W. Halogen chemistry of the red alga Asparagopsis. Phytochemistry 1977, 16, 367-374. [CrossRef]

15. Zárate, R.; Portillo, E.; Teixidó, S.; Carvalho, M.A.A.P.D.; Nunes, N.; Ferraz, S.; Seca, A.M.L.; Rosa, G.P.; Barreto, M.C. Pharmacological and cosmeceutical potential of seaweed beach-casts of macaronesia. Appl. Sci. 2020, 10, 5831. [CrossRef]

16. Blois, M.S. Antioxidant determinations by the use of a stable free radical. Nature 1958, 181, 1199-1200. [CrossRef]

17. Re, R.; Pellegrini, N.; Proteggente, A.; Pannala, A.; Yang, M.; Rice-Evans, C. Antioxidant activity applying an improved ABTS radical cation decolorization assay. Free Radic. Biol. Med. 1999, 26, 1231-1237. [CrossRef]

18. Decker, E.A.; Welch, B. Role of ferritin as a lipid oxidation catalyst in muscle food. J. Agric. Food Chem. 1990, $38,674-677$. [CrossRef]

19. Ellman, G.L.; Courtney, K.D.; Andres Jr, V.; Featherstone, R.M. A new and rapid colorimetric determination of acetylcholinesterase activity. Biochem. Pharmacol. 1961, 7, 88-95. [CrossRef]

20. Arruda, M.; Viana, H.; Rainha, N.; Neng, N.R.; Rosa, J.S.; Nogueira, J.M.; Barreto, M.C. Anti-acetylcholinesterase and antioxidant activity of essential oils from Hedychium gardnerianum Sheppard ex Ker-Gawl. Molecules 2012, 17, 3082-3092. [CrossRef] [PubMed]

21. Shimizu, K.; Kondo, R.; Sakai, K.; Lee, S.H.; Sato, H. The inhibitory components from Artocarpus incisus on melanin biosynthesis. Planta Med. 1998, 64, 408-412. [CrossRef]

22. Manosroi, A.; Jantrawut, P.; Akihisa, T.; Manosroi, W.; Manosroi, J. In vitro anti-aging activities of Terminalia chebula gall extract. Pharm. Biol. 2010, 48, 469-481. [CrossRef] [PubMed]

23. Mandl, I.; MacLennan, J.D.; Howes, E.L.; De Bellis, R.H.; Sohler, A. Isolation and characterization of proteinase and collagenase from Cl. histolyticum. J. Clin. Investig. 1953, 32, 1323-1329. [CrossRef] [PubMed]

24. Ndlovu, G.; Fouche, G.; Tselanyane, M.; Cordier, W.; Steenkamp, V. In vitro determination of the anti-aging potential of four southern African medicinal plants. BMC Complement. Altern. Med. 2013, 13, 304. [CrossRef] [PubMed]

25. Halket, J.M.; Zaikin, V.G. Derivatization in mass spectrometry-1. Silylation. Eur. J. Mass Spectro. 2003, 9, 1-21. [CrossRef] [PubMed]

26. Seca, A.M.L.; Gouveia, V.L.M.; Barreto, M.C.; Silva, A.M.S.; Pinto, D.C.G.A. Comparative study by GC-MS and chemometrics on the chemical and nutritional profile of Fucus spiralis L. juvenile and mature life-cycle phases. J. Appl. Phycol. 2018, 30, 2539-2548. [CrossRef]

27. Genovese, G.; Tedone, L.; Hamann, M.T.; Morabito, M. The Mediterranean red alga Asparagopsis: A source of compounds against Leishmania. Mar. Drugs 2009, 7, 361-366. [CrossRef]

28. Gribble, G.W. Biological activity of recently discovered halogenated marine natural products. Mar. Drugs 2015, 13, 4044-4136. [CrossRef]

29. Rocha, D.H.A.; Seca, A.M.L.; Pinto, D.C.G.A. Seaweed secondary metabolites in vitro and in vivo anticancer activity. Mar. Drugs 2018, 16, 410. [CrossRef] [PubMed]

30. Mandrekar, V.K.; Gawas, U.B.; Majik, M.S. Brominated molecules from marine algae and their pharmacological importance. In Studies in Natural Products Chemistry, Atta-ur-Rahman; Elsevier: Amsterdam, The Netherlands, 2019; Volume 61, pp. 461-490.

31. Pereira, R.B.; Pinto, D.C.G.A.; Pereira, D.M.; Gomes, N.G.M.; Silva, A.M.S.; Andrade, P.B.; Valentão, P. UHPLC-MS/MS profiling of Aplysia depilans and assessment of its potential therapeutic use: Interference on iNOS expression in LPS-stimulated RAW 264.7 macropheges and caspase-mediated pro-apoptotic effect on SH-SY5Y cells. J. Func. Foods 2017, 37, 164-175. [CrossRef]

32. Zhong, B.; Robinson, N.A.; Warner, R.D.; Barrow, C.J.; Dunshea, F.R.; Suleria, H.A.R. LC-ESI-QTOF-MS/MS Characterization of seaweed phenolics and their antioxidant potential. Mar. Drugs 2020, 18, 331. [CrossRef] [PubMed]

33. Harvey, D.J.; Vouros, P. Mass spectrometric fragmentation of trimethylsilyl and related alkylsilyl derivatives. Mass Spectro. Rev. 2020, 39, 105-211. [CrossRef] [PubMed]

34. Greff, S.; Zubia, M.; Genta-Jouve, G.; Massi, L.; Perez, T.; Thomas, O.P. Mahorones, highly brominated cyclopentenones from the red alga Asparagopsis taxiformis. J. Nat. Prod. 2014, 77, 1150-1155. [CrossRef] 
35. Paul, N.A.; De Nys, R.; Steinberg, P.D. Chemical defence against bacteria in the red alga. Mar. Ecol. Prog. Ser. 2006, 306, 87-101. [CrossRef]

36. Mata, L.; Wright, E.; Owens, L.; Paul, N.; de Nys, R. Water-soluble natural products from seaweed have limited potential in controlling bacterial pathogens in fish aquaculture. J. Appl. Phycol. 2013, 25, 1963-1973. [CrossRef]

37. Harrison, L.M.; Balan, K.V.; Babu, U.S. Dietary fatty acids and immune response to food-borne bacterial infections. Nutrients 2013, 5, 1801-1822. [CrossRef] [PubMed]

38. Pereira, H.; Barreira, L.; Figueiredo, F.; Custódio, L.; Vizetto-Duarte, C.; Polo, C.; Rešek, E.; Engelen, A.; Varela, J. Polyunsaturated fatty acids of marine macroalgae: Potential for nutritional and pharmaceutical applications. Mar. Drugs 2012, 10, 1920-1935. [CrossRef] [PubMed]

39. Mancini, A.; Imperlini, E.; Nigro, E.; Montagnese, C.; Daniele, A.; Orrù, S.; Buono, P. Biological and nutritional properties of palm oil and palmitic acid: Effects on health. Molecules 2015, 20, 17339-17361. [CrossRef] [PubMed]

40. Agostoni, C.; Moreno, L.; Shamir, R. Palmitic acid and health: Introduction. Crit. Rev. Food Sci. Nutr. 2016, 56, 1941-1942. [CrossRef] [PubMed]

41. Bazes, A.; Silkina, A.; Douzenel, P.; Faÿ, F.; Kervarec, N.; Morin, D.; Berge, J.-P.; Bourgougnon, N. Investigation of the antifouling constituents from the brown alga Sargassum muticum (Yendo) Fensholt. J. Appl. Phycol. 2009, 21, 395-403. [CrossRef]

42. Broadgate, W.J.; Malin, G.; Küpper, F.C.; Thompson, A.; Liss, P.S. Isoprene and other non-methane hydrocarbons from seaweeds: A source of reactive hydrocarbons to the atmosphere. Mar. Chem. 2004, 88, 61-73. [CrossRef]

43. Albuquerque, H.M.T.; Santos, C.M.M.; Silva, A.M.S. Cholesterol-based compounds: Recent advances in synthesis and applications. Molecules 2019, 24, 116. [CrossRef]

44. Burreson, B.J.; Moore, R.E.; Roller, P.P. Volatile halogen compounds in the alga Asparagopsis taxiformis (Rhodophyta). J. Agric. Food. Chem. 1976, 24, 856-861. [CrossRef]

45. Máximo, P.; Ferreira, L.M.; Branco, P.; Lima, P.; Lourenço, A. Secondary metabolites and biological activity of invasive macroalgae of Southern Europe. Mar. Drugs 2018, 16, 265. [CrossRef] [PubMed] 